ఠ

\title{
Refractive lenticule extraction (ReLEx) through a small incision (SMILE) for correction of myopia and myopic astigmatism: current perspectives
}

This article was published in the following Dove Press journal:

Clinical Ophthalmology

3 October 2016

Number of times this article has been viewed

\author{
Alper Ağca' \\ Ahmet Demirok ${ }^{2}$ \\ Yusuf Yıldırım' \\ Ali Demircan' \\ Dilek Yașa' \\ Ceren Yeșilkaya' \\ Irfan Perente' \\ Muhittin Tașkapılı' \\ 'Beyoğlu Eye Research and \\ Training Hospital, ${ }^{2}$ Department of \\ Ophthalmology, Istanbul Medeniyet \\ University, Istanbul, Turkey
}

\begin{abstract}
Small-incision lenticule extraction (SMILE) is an alternative to laser-assisted in situ keratomileusis (LASIK) and photorefractive keratectomy (PRK) for the correction of myopia and myopic astigmatism. SMILE can be performed for the treatment of myopia $\leq-12 \mathrm{D}$ and astigmatism $\leq 5 \mathrm{D}$. The technology is currently only available in the VisuMax femtosecond laser platform. It offers several advantages over LASIK and PRK; however, hyperopia treatment, topography-guided treatment, and cyclotorsion control are not available in the current platform. The working principles, potential advantages, and disadvantages are discussed in this review. Keywords: SMILE, small-incision lenticule extraction, femtosecond laser, laser in situ keratomileusis, corneal biomechanics
\end{abstract}

\section{Introduction}

Laser-assisted in situ keratomileusis (LASIK) is the most commonly applied refractive corneal surgery procedure. Refractive lenticule extraction (ReLEx) is an alternative to LASIK for the correction of myopia and myopic astigmatism. ReLEx can be used to treat myopia of up to $-12 \mathrm{D}$ and astigmatism of up to $5 \mathrm{D}$. The technology is currently only available in the VisuMax (Carl Zeiss Meditec AG, Jena, Germany) femtosecond laser platform. This platform enables us to perform two different procedures: femtosecond lenticule extraction (FLEx) and small-incision lenticule extraction (SMILE). The early outcomes of FLEx surgery, which is considered a step toward transition to SMILE, were first published in 2008, whereas the early outcomes of SMILE were first reported in 2011. ${ }^{1,2}$ SMILE became commercially available in 2012, and it is also a lamellar refractive surgery method, as is LASIK.

\section{Lamellar refractive surgery procedures: SMILE and LASIK}

Pallikaris et al unveiled the LASIK in $1990 .{ }^{3}$ As in the automated lamellar keratoplasty procedure, in LASIK a microkeratome incision and a hinged flap are initially created; however, in the second phase, the relevant lenticule is eliminated using excimer laser photoablation instead of performing a second keratome incision to extract the lenticule from the stroma. Indeed, the target of the process started by Barraquer in $1949^{4}$ was to remove an intrastromal lenticule from the cornea through grinding (keratomileusis), an incision (automated lamellar keratoplasty) or laser ablation (LASIK). Pulling up the stroma to reach the target tissue has been an essential step in all procedures. However, as it is now possible to generate an intrastromal incision via femtosecond
Correspondence: Alper Ağca Beyoğlu Eye Research and Training Hospital, Galata, Beyoğlu, Istanbul 34349, Turkey

Email agcaalper@yahoo.com 
A
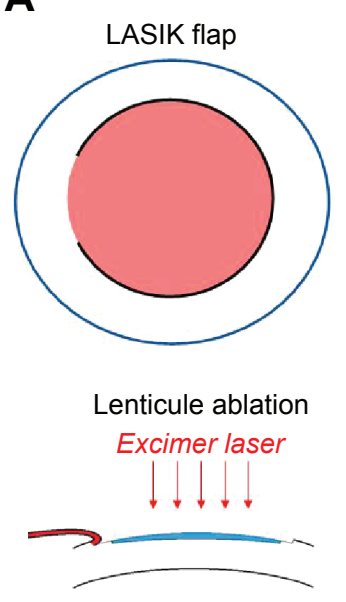

B Intrastromal lenticule

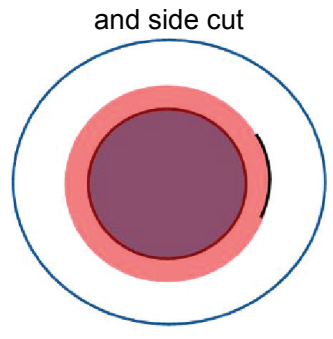

Lenticule extraction

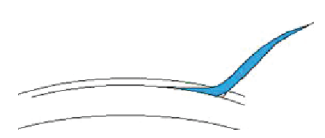

Figure I Schematic drawings of LASIK (A) and SMILE (B).

Abbreviations: LASIK, laser-assisted in situ keratomileusis; SMILE, small-incision lenticule extraction.

lasers, we can prepare the lenticule to be removed without touching or damaging the tissue above it. The purpose of lenticule extraction is to remove the "same tissue" eliminated through ablation in LASIK surgery without creating a flap on the cornea (Figure 1).

\section{Essential features of femtosecond lasers}

Laser-tissue interactions may be generated through various methods, including photoablation, photocoagulation, photochemical reactions, photovaporization, and photodisruption. Different procedures require different laser-tissue interaction techniques. For instance, the ultraviolet radiation at a wavelength of $193 \mathrm{~nm}$ used in the excimer-laser method breaks the bonds between the molecules and thus provides "ablation". Because radiation of this wavelength cannot penetrate into the cornea, it can be applied only for surface ablation. In other words, it is not possible to achieve intrastromal ablation with an excimer laser without lifting a flap and exposing the surface of the intrastromal target tissue. On the other hand, the $1,043 \mathrm{~nm}$ infrared laser beam of the VisuMax femtosecond laser platform can pass through transparent layers, and in this way it can be easily focused on any intrastromal area. A similar wavelength is also used in neodymium-doped yttrium aluminum-garnet laser capsulotomy procedures.

A femtosecond is $10^{-15}$ of a second. Optical breakdown can be produced through the nonlinear absorption of energy by the target tissue if an energy input above a critical threshold is achieved by administering the energy to a very small area (a few square microns) within a very short time period (femtoseconds). As a result of the optical breakdown, the target tissue transforms into plasma.

Plasma is a gas-like, highly ionized form of matter that consists of free charged particles, such as electrons. The shorter the duration of energy administration and the smaller the target area becomes, the lower the minimum energy required for plasma generation. The target tissue that is transformed into plasma is ablated by plasma-induced ablation. However, the effect of the femtosecond laser on the corneal stroma is not limited to plasma-induced ablation.

Plasma formation and its impact on the surrounding tissues are called photodisruption. Photodisruption is different from the photoablation process in that photoablation breaks the bonds between molecules in the immediate target area (the spot size); however, in photodisruption, although the plasma-induced ablation occurs within a very small area in which plasma is formed, the main effect of the laser arises from the spreading of the shock wave after plasma formation. This shock wave creates tissue dissection and a cavitation bubble in the surrounding tissue. In this way, although there are gaps between laser spots, the dissection plane can be continuous and an intrastromal incision can be created.

When the diameter of the spot becomes smaller, the amount of energy necessary for the creation of optical breakdown (creation of plasma) reduces. Different femtolaser platforms have different spot sizes depending on their optical properties (eg, the numerical apertures of their lenses). The diameter of the dissection field created by the laser energy focused on a particular spot extends to a much larger area than the spot itself and depends on the energy level. This means that in excimer-laser procedures, the diameter of the spot determines the size of the affected area, whereas in femtosecond laser procedures, the energy of the spot determines the size of the affected area.

It is possible to alter the spot separation and the spot energy in the VisuMax femtosecond laser platform. For faster treatment, the spot energy is increased so that the dissection diameter around the focus area of individual spots is extended. This permits increased spot separation (the space between the individual laser spots), allowing the creation of the same incision with a smaller number of spots and thereby leading to a more rapid treatment. When the spots are closer together and the energy is low, the quality of the femtosecond laser may increase; however, a larger number of spots will be needed to achieve the same incision, and thus the treatment will be slower. Although closer spots and lower energy increase the surface quality of the cut, the longer treatment time is an adverse effect. The gas bubbles created during each laser pulse diffuse into the stroma, making the stromal surface and thus the cut surface irregular. Therefore, a faster cut can create a more regular surface. 
Table I Routine surgical parameters employed by Ağca et al during small-incision lenticule extraction

\begin{tabular}{ll}
\hline Patient interface & Type S \\
Side-cut position & Superotemporal \\
Side-cut length $(\mathrm{mm})$ & $2.0-3.0$ \\
Side-cut angle (degrees) & 90 \\
Lenticule-edge angle (degrees) & 135 \\
Minimum lenticule thickness $(\mu \mathrm{m})$ & 15 \\
Lenticule diameter $(\mathrm{mm})$ & 6.5 \\
Cap diameter $(\mathrm{mm})$ & 7.5 \\
Spot separation $(\mu \mathrm{m})$ & 4.5 \\
Spot energy $(\mathrm{n})$ & 160 \\
\hline
\end{tabular}

\section{Surgical method}

A curved interface, which provides approximate alignment with the corneal surface, is used on the VisuMax femtosecond laser platform. The most significant advantage of this curvedapplanation interface is that it causes a smaller increase in intraocular pressure compared to other systems that use flatapplanation interfaces. Once it is certain that good contact has been established between the cornea and the interface, the vacuum is activated by pressing the button on the joystick. After this step, the foot switch is pressed and the machine starts to make the necessary incisions. The routine surgical parameters employed during SMILE are summarized in Table 1 and Figure 2.

The cavitation bubbles appearing during the creation of the femtosecond incisions create a temporary opacity and prevent a new incision plane under the current incision.
Therefore, all incisions in both FLEx and SMILE surgeries are generated from posterior to anterior. In both surgical methods, the required surgical incisions are created in five steps. First, a lamellar incision plane creates the posterior surface of the lenticule (base of the lenticule that is to be extracted), and separates it from the rest of the stroma (Figure 2A, incision 1). This incision is created from the periphery to the center, and determines the refractive correction. It is thus recommended that if this first incision is left half-finished for any reason, then FLEx or SMILE procedures should be terminated to avoid the risk of irregular astigmatism; a flap should be created, and the surgery should be carried out as femtosecond LASIK. Following the completion of the lamellar incision, a $360^{\circ}$ vertical incision is made to create the edge of the lenticule (Figure 2A, incision 2). The manufacturer recommends the creation of a $15 \mu \mathrm{m}$ edge thickness to avoid any tearing during extraction. The minimum thickness of the edge of the lenticule can be adjusted on the menu of the device. When the incision on the edge is created, a cap incision is made from the center to the periphery to create the anterior surface of the lenticule (Figure 2A, incision 3). When this step is completed, the lenticule for removal has been created between the base and cap incisions. The incision required for the last step differs between the FLEx and SMILE procedures.

\section{FLEx procedure}

A ring-shaped incision is created following the projection of the edge of the lamellar incision on the corneal surface.

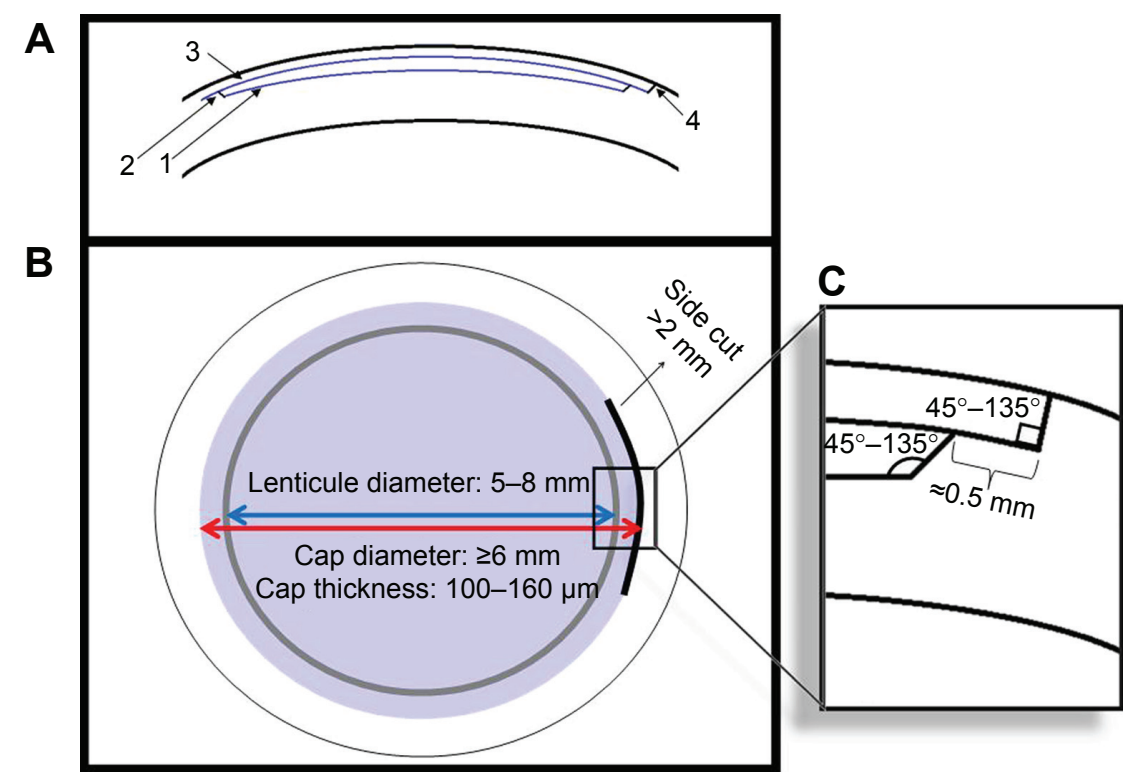

Figure $\mathbf{2}$ Incision geometry and ranges for surgical parameters.

Notes: Incision geometry of small-incision lenticule-extraction surgery (A): refractive cut (I), lenticule side cut (2), cap (3), and side cut (4). Ranges for surgical parameters (B) and edges of the cap and lenticule (C). 
A portion (approximately $50^{\circ}$ or less) is left uncut to function as a hinge. In this way, a flap is created on the lenticule. The width of the hinge can be adjusted from the menu before the surgery. When this incision is made, the vacuum ceases automatically. With the joystick, the position of the patient's bed is altered slightly to lie under the surgical microscope. Once under the surgical microscope, the lenticule-flap interface is entered with a spatula, the remaining tissue bridges are separated, and the flap is lifted. The lenticule is peeled from the stromal bed with forceps, and the surgery is completed with the closure of the flap.

\section{SMILE procedure}

An incision of almost $3 \mathrm{~mm}$ in length is created on the projection of the lamellar incision on the corneal surface, reaching to the edge of the lenticule (Figure 2A, incision 4). The width of the incision can be adjusted from the device menu before the surgery. When this incision is made, the vacuum ceases automatically. With the joystick, the position of the patient's bed is altered slightly to lie under the surgical microscope.

Once the bed is under the surgical microscope, a spatula is advanced through the $3 \mathrm{~mm}$ incision. First, the tissue bridges between the lenticule and the anterior stroma and then the tissue bridges between the lenticule and the posterior stroma are dissected. After the remaining stromal tissue bridges are eliminated, the lenticule is removed from the stroma with forceps inserted through the side incision. In both methods, the extracted lenticule is a wave front-optimized lenticule.

\section{Incomplete treatment}

Incisions are performed in four distinct steps, as shown in Figure 2A and B: 1) lenticule base incision (the refractive cut), 2) lenticule edge incision, 3) lenticule cap incision, and 4) side-cut incision. In the event that the surgery is aborted as a consequence of vacuum loss or for another reason, a warning message appears on the monitor specifying at which step the procedure has ceased, and what percentage of the relevant step has been completed. If the surgeon chooses the "Continue" option, following recentralization and vacuum generation, the procedure reinitiates from the beginning of the step that has been left incomplete and incisions continue to be created. However, if the procedure is aborted when more than $10 \%$ of the first stage, ie, the creation of the lenticule base incision, has already been completed but the second stage has not yet begun, the transition to femtosecond LASIK becomes obligatory so as to avoid an irregular refractive cut. The utmost attention should be paid to the second centralization so that it is in alignment with the first incision. Also, if the lenticule edge incision is to be repeated, the diameter of the edge incision needs to be reduced, in order to guarantee that the edge incision does not exceed the borders of the lenticule. Additionally, the depth of the edge incision should be increased by at least $5 \mu \mathrm{m}$ to compensate for tissue thickening, which is likely to occur due to gas bubbles. If the third stage, cap incision, needs to be repeated, its diameter should be large enough to ensure that it exceeds the limits of the lenticule incision created in the first stage. Some surgeons prefer to keep the difference between the lenticule incision and cap incision large from the beginning (eg, $1.2 \mathrm{~mm}$ instead of $1 \mathrm{~mm}$ ), so as to ensure covering of the lenticule base in the event that suction loss occurs and the second docking is not well centered on the first one.

\section{Enhancement after SMILE}

If a need to repeat the refractive correction arises during follow-up after FLEx, excimer-laser treatment can be implemented by lifting up the flap. Although there are not many examples in the literature, it is possible in our experience to administer additional therapy through excimerlaser treatment.

The simplest way to perform an enhancement after SMILE is photorefractive keratectomy (PRK). Recently, a procedure called Circle (Carl Zeiss Meditec AG) was developed to convert the original SMILE cap into a complete flap. ${ }^{5}$ In this procedure, the VisuMax femtosecond laser platform (Carl Zeiss Meditec AG) is used to create, 1) an incision plane encircling the original cap cut as a lamellar ring, 2) a side cut with a hinge around the new incision plane, and 3) a junction cut, which allows the original cap and the new incision plane to be part of one larger surface.

As lenticule extraction is an alternative to LASIK surgery, it is important to compare the advantages and disadvantages of each. In the following sections, we compare some significant features of LASIK and SMILE and briefly discuss the advantages and disadvantages of each method.

\section{Corneal ectasia}

Corneal ectasia is one of the complications of LASIK that is most feared, and all possible measures should be taken to avoid its occurrence. It is not possible to assess the incidence of post-LASIK ectasia accurately, because incidence varies depending on the amount of refractive error corrected in the patient group, the amount of ablation, the residual stromal bed, the age of the patients, and the preoperative topographic conditions.

Therefore, the incidence rates reported in the literature range between $0.06 \%$ and $0.8 \%$ in different patient groups. ${ }^{6,7}$ The weakening of the biomechanics of the anterior stroma 
because of the flap and the ablation is thought to be the cause of ectasia following LASIK.

The anatomy varies between the anterior and posterior stroma. Although the collagen lamellae are narrower in the anterior part of the cornea, they show numerous, complex branching patterns that are intertwined in some way. On the other hand, in the posterior part of the cornea, the collagen lamellae are wider, show fewer branches, and are relatively regular and orthogonal. The nested structure of the anterior stroma forms a more resistant biomechanical roof. ${ }^{8}$

When the corneal flap is created, the biomechanical support from the flap stroma is eliminated. and it does not return to normal even if the flap is repositioned in its original position. Because the corneal flap eliminates the support from the anterior part of the cornea, which is the most resistant section, the corneal biomechanics become significantly disrupted. Cartwright et al carried out a study using animal eyes and examined the stress-strain graphics by dividing the eyes into three categories according to the type of incision: flap-side incision, lamellar flap incision, and complete flap incision. ${ }^{9}$ In this study, whereas a $33 \%$ strength loss was detected in the full-flap incision group, the loss of strength in the flapside incision group (without the creation of a flap) was very similar, at $32 \%$. However, the loss of strength in the lamellar incision group (without the creation of a flap) was $5 \%$.

When a flap is created, the side incision is responsible for the loss of strength in the stroma. Creating an intrastromal lamellar incision alone does not result in a significant loss in corneal resistance. Other factors being equal, the absence of a flap in SMILE (there is a flap in LASIK) would result in

A

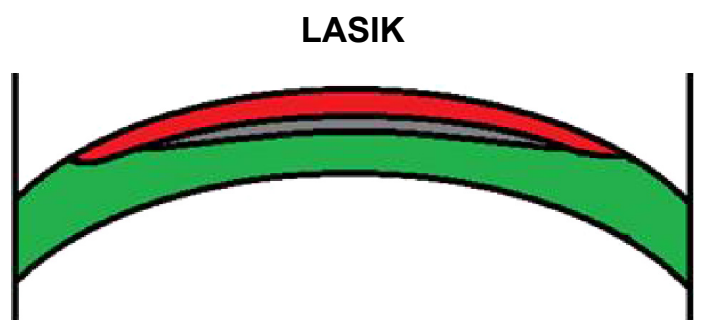

B

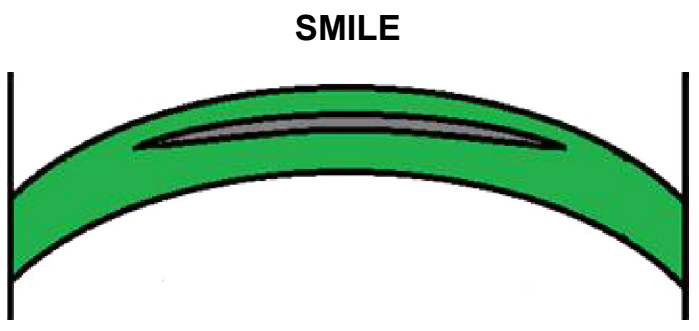

Figure 3 Comparison of LASIK flap (A) and SMILE cap (B). The anterior stroma is relatively stronger in SMILE.

Abbreviations: LASIK, laser-assisted in situ keratomileusis; SMILE, small-incision lenticule extraction. improved protection of corneal resistance (Figure $3 \mathrm{~A}$ and $\mathrm{B}$ ). It is not known whether this is reflected in the incidence of ectasia (ie, whether it has a clinically significant effect), but the literature-reported incidence of ectasia after SMILE is extremely rare. ${ }^{10,11}$

In another study, we compared the measurements of corneal hysteresis $(\mathrm{CH})$ and corneal resistance factor $(\mathrm{CRF})$ in LASIK-treated and SMILE-treated eyes, and found that $\mathrm{CH}$ and $\mathrm{CRF}$ levels declined in both groups in the postoperative period, but there was no significant difference between the groups. ${ }^{12}$ Nevertheless, although $\mathrm{CH}$ and $\mathrm{CRF}$ values are associated with corneal biomechanics, they are not sufficient to demonstrate the resistance of the cornea to deformation. Indeed, it is known that Young's modulus for the cornea increases after a cross-link procedure, but $\mathrm{CH}$ and $\mathrm{CRF}$ values do not significantly change after cross-linking. ${ }^{13}$

\section{Flap-related complications}

The necessity to create a flap in the LASIK procedure may give rise to flap-related complications. Striae developing early in the intraoperative or postoperative period and flap damage that occurs after trauma are among the major flap-related complications. The LASIK flap never strongly adheres to the stroma below it, and thus it risks displacement with trauma, even many years after the surgery. As a flap is not created in SMILE surgery, such a complication is not possible. For this reason, we believe that SMILE is the safest corneal refractive surgery procedure for patients at risk of trauma, especially if their refractive error is high. We have not encountered any complications in SMILE procedures used in cases with a spherical equivalent up to $10 \mathrm{D}$ at our hospital.

\section{Dry-eye syndrome}

Corneal nerves originate from the long posterior ciliary nerves that are connected to the ophthalmic branch of the trigeminal nerve. These nerves penetrate the sclera around the optic nerve and reach the limbus. Corneal nerves radially enter the cornea from the limbus at a depth of about 250-300 $\mu \mathrm{m}$ and spread to the corneal stroma. These stromal nerves give off vertical branches toward the anterior surface, which perforate Bowman's layer and form a subbasal plexus in the plane between the basal membrane of the epithelium and Bowman's layer. The branches separated from the subbasal plexus terminate as free nerve endings scattered among the epithelial cells. ${ }^{14}$

Innervation plays a major role in the maintenance of the ocular surface. Although dry-eye syndrome is relatively frequent after LASIK, it does not typically cause crucial problems. However, it can lead to serious morbidity in 
some patients. It is hard to determine a clear incidence rate for post-LASIK dry-eye syndrome, because the definition varies between publications and there is often a discrepancy between symptoms and clinical findings. The incidence of post-LASIK dry eye causing discomfort in patients is approximately $10 \%$ or less. ${ }^{15}$

Dry-eye syndrome developing after LASIK surgery results mainly from damage to the corneal sensory nerves. The flap created during LASIK is almost entirely dissected, except for a limited number of nerves entering from the hinge area. Even though it was previously recommended to generate a nasal hinge to protect innervation, it has been shown that the number of nerve fibers entering through each quadrant is equal. ${ }^{14}$ Therefore, the position of the flap hinge does not have a protective effect on nerve fibers. It should be noted that the nerve fibers enter the cornea from limbus at a deeper level compared to the level of the lenticule of flap. ${ }^{14}$

Considering the distribution of the nerve fibers mentioned, the lamellar incision rather than the side-cut incision of the flap is expected to be responsible for the injury of nerve fibers, and the same injury may arise as a result of lamellar incision in lenticule-extraction procedures. Nevertheless, as both the lamellar incision and the side incision are smaller in the SMILE procedure, nerve fibers are expected to be slightly better preserved in SMILE (Figure 4A and B). In a group of patients who had SMILE for one eye and LASIK for the other, we measured the corneal sensitivity with the Cochet-Bonnet esthesiometer and obtained results in favor of the SMILE procedure. ${ }^{16}$ The difference was statistically
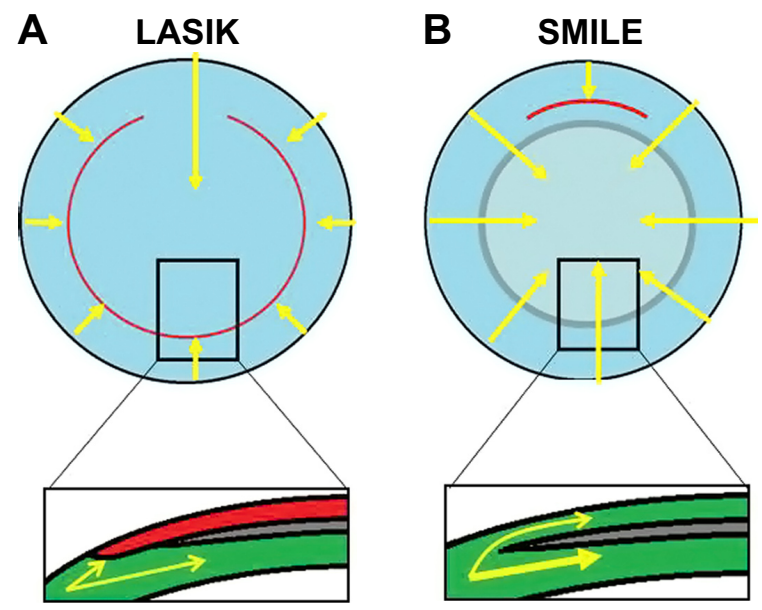

Figure 4 Corneal nerves (arrows) in LASIK (A) and SMILE (B).

Notes: Lamellar dissection plane below the flap (A) and cap (B) prevent deep stromal nerves from reaching the corneal surface perpendicularly. However, the area of a SMILE cap is typically smaller than the area of a LASIK flap. Furthermore, the length of the side cut is greatly reduced in SMILE (B).

Abbreviations: LASIK, laser-assisted in situ keratomileusis; SMILE, small-incision lenticule extraction. significant, but limited to the early postoperative period. Despite this, we did not identify any difference in dry-eye parameters. It can be concluded from the results of this study that although SMILE causes less damage to nerve fibers, it does not cause a clinically significant difference. A deeper lamellar incision and a smaller lenticule diameter may reduce the risk of nerve damage.

\section{Epithelial ingrowth}

Epithelial ingrowth has been reported at different rates for different keratomes, and its incidence ranges from $0.92 \%$ to $14.7 \% .{ }^{17-20}$ However, the incidence of epithelial ingrowth that requires surgical intervention is much lower, and ranges between 0 and $3 \% .{ }^{17-20}$ As the epithelial tissue proceeds to the stromal interface through the side incisions of the flap, due to the fact that there is only an approximately $3 \mathrm{~mm}$ side incision in SMILE, it can be theoretically claimed that the risk of epithelial ingrowth is reduced in SMILE. We have not encountered a clinically significant epithelial ingrowth case after any of the LE procedures we have performed. However, in this regard, it will be necessary to follow up a larger number of patients for longer periods, so as to provide more accurate results.

\section{Diffuse lamellar keratitis}

The literature-reported incidence of diffuse lamellar keratitis (DLK) is very variable (range $0.1 \%-12.4 \%$ ), and it is very rare today. ${ }^{21,22}$ Although femtosecond lasers are safer than mechanical microkeratomes in many contexts, they do not have any advantages over modern mechanical microkeratomes regarding the incidence of DLK. In fact, higher DLK incidence has been reported in cases where femtosecond lasers have been used. ${ }^{23}$

However, the use of lower energy in femtosecond lasers has reduced DLK incidence. As LE surgery requires the use of a higher amount of total laser energy (creation of two lamellar planes instead of one) compared to a femtosecond LASIK surgery, performed using the same platform, the incidence of DLK might be expected to increase. However, DLK after SMILE is a rare complication. In a retrospective study of 1,112 eyes Zhao et al reported that 18 eyes $(1.6 \%)$ developed DLK, and all of them resolved completely with topical steroid therapy. ${ }^{24}$

\section{Refractive and visual outcomes}

Refractive outcomes obtained after LE have been found to be similar to refractive results of modern femtosecond LASIK surgery. ${ }^{25,26}$ Just as with LASIK surgery, refractive results 
stabilize in a short time after LE. Compared to LASIK, LE is equally effective, secure, and predictable regarding refractive outcomes and visual acuity.

The main difference and perhaps the only disadvantage of LE is that although the recovery of objective refraction is as quick as in LASIK, visual acuity does not recover as rapidly. ${ }^{26}$ In other words, even if the objective refraction of the patient reaches $\pm 0.25 \mathrm{D}$, which may be considered emmetropia, in the early postoperative period, visual acuity may remain at $0.7-0.8$ or at a lower level. It may take 1 month or more for some patients to achieve satisfactory uncorrected and/or distance corrected visual acuity after surgery. Either microirregularities on the surface of the cornea and the interface where the lenticule is extracted or the prolonged surgical manipulations may be responsible for the long recovery process. In a previous study, we analyzed patients who underwent LASIK for one eye and SMILE for the other eye, and followed up the patients with confocal microscopy in the early postoperative period. ${ }^{27}$ The study showed that the interface reflectivity of the SMILE-treated eyes was statistically significantly higher during the first 3 months after surgery compared to the interface reflectivity of the LASIK-treated eye. This may be an indicator that the activation of keratocytes was greater in SMILE-treated eyes. Although the period of higher interface reflectivity coincides with the prolonged recovery of visual acuity, it is not clear if there is a cause-effect relationship between these.

\section{High-order aberrations}

The lenticule extracted through the LE procedure is a wave front-optimized lenticule, and in this regard does not differ from the LASIK procedure. All studies comparing lenticule extraction with a similar control group of patients demonstrated that the induction of the high-order aberrations was either the same or lower in the LE-treated eyes compared to the eyes treated with femtosecond LASIK. ${ }^{28,29}$

\section{Disadvantages}

SMILE surgery is currently available only on a single femtosecond laser platform. We think that the biggest deficiency of this platform is the absence of an eye-tracker system to correct cyclotorsion. This is a theoretically significant disadvantage for the patient with severe astigmatism when compared with the excimer-laser platforms that compensate for cyclotorsion. The addition of such technology to distinctive femtosecond laser platforms may increase competition in the field and thus accelerate the development of such software features. Also, it is still unclear which technique would be most appropriate if an additional treatment were needed because of inadequate correction, excessive correction, or inappropriate correction of a refractive error of the eye. Theoretically, there is no factor hindering the use of surface ablation or femtosecond LASIK for additional therapy, but an excimer laser is necessary in that case. The manufacturer of the device is currently developing software that will allow the use of lenticule extraction for additional therapies.

Another disadvantage of the SMILE procedure is that it is not yet commercially available for use in hyperopic patients. A study on the results of hyperopic SMILE has been published; however, the results were not satisfactory. Topography-guided treatments are not possible with the VisuMax femtosecond laser platform, and this may be a disadvantage in treating corneas with an irregular topography and a large degree of preexisting high-order aberrations.

Furthermore, the current SMILE platform does not have a cyclotorsion-compensation system. Cyclotorsion in the lying position is generally $<5^{\circ}$, and it is very rare to see cyclotorsion around $10^{\circ}$. Even a $10^{\circ}$ cyclotorsion would not create a refractive surprise if the patient had a small amount of astigmatism, since residual astigmatism would be $33 \%$ of the original (ie, a patient with a $0.75 \mathrm{D}$ preoperative astigmatism would have a $0.25 \mathrm{D}$ residual astigmatism, which would not create a clinical problem). However, the same amount of cyclotorsion (although it is very rare) would result in approximately $1 \mathrm{D}$ residual astigmatism in a patient with $3 \mathrm{D}$ preoperative astigmatism (ie, $33 \%$ of $3 \mathrm{D}$ ). Therefore, if the patient had a large amount of astigmatism, it would be safer to treat with an excimer-laser platform using cyclotorsion compensation. We have also noted that the docking and suction maneuver itself sometimes creates additional cyclotorsion in the eye.

\section{Conclusion}

Lenticule extraction is a safe and effective method for the treatment of myopia and myopic astigmatism, and appears to be a surgical method that combines the advantages of LASIK and PRK. Compared to PRK, visual acuity improves much more quickly, refractive outcomes become stabilized within a shorter time, there is no risk of haze in the postoperative period, and higher refractive errors can be corrected through lenticule extraction.

On the other hand, when LE is compared to LASIK, the cornea remains biomechanically stronger and more resistant to trauma after the surgery (as in PRK). However, recovery of visual acuity occurs a little more slowly than in LASIK, and wave front- or topography-guided treatment is not possible. Moreover, the current platform does not have cyclotorsion 
compensation, and hypermetropia treatment is not yet possible. Despite these disadvantages, it should be kept in mind that the flap is created because of the "necessity" to reach the target tissue in LASIK surgery. It is evident that the need to create the flap will be eliminated with technological advances in the future. Lenticule-extraction surgery is a critical step in this direction, and constitutes a safe alternative to LASIK surgery in its current form. We believe that with improvements in femtosecond laser platforms, the use of laser extraction will become widespread in the near future.

\section{Disclosure}

The authors report no conflicts of interest in this work.

\section{References}

1. Sekundo W, Kunert K, Russman C, et al. First efficacy and safety study of femtosecond lenticule extraction for the correction of myopia: six month results. J Cataract Refract Surg. 2008;34(9):1513-1520.

2. Sekundo W, Kunert KS, Blum M. Small incision corneal refractive surgery using the small incision lenticule extraction (SMILE) procedure for the correction of myopia and myopic astigmatism: results of a 6 month prospective study. Br J Ophthalmol. 2011;95(3):335-359.

3. Pallikaris IG, Papatzanaki ME, Stathi EZ, Frenschock O, Georgiadis A. Laser in situ keratomileusis. Lasers Surg Med. 1990;10(5):463-468.

4. Barraquer JI. Queratoplastia refractiva. Estudios e Informaciones Oftalmologicas. 1949;10:1-21.

5. Riau A, Ang H, Lwin N, Chaurasia S, Tan D, Mehta J. Comparison of four different VisuMax Circle patterns for flap creation after small incision lenticule extraction. J Refract Surg. 2013;29(4):236-244.

6. Binder PS. Analysis of ectasia after laser in situ keratomileusis: risk factors. J Cataract Refract Surg. 2007;33(9):1530-1538.

7. Condon PI, O'Keefe M, Binder PS. Long-term results of laser in situ keratomileusis for high myopia: risk for ectasia. J Cataract Refract Surg. 2007;33(4):583-590.

8. Komai Y, Ushiki T. The three-dimensional organization of collagen fibrils in the human cornea and sclera. Invest Ophthalmol Vis Sci. 1991;32(8):2244-2258.

9. Cartwright NE, Tyrer JR, Jaycock PD, Marshall J. Effects of variation in depth and side cut angulations in LASIK and thin-flap LASIK using a femtosecond laser: a biomechanical study. J Refract Surg. 2012; 28(6):419-425.

10. El-Naggar MT. Bilateral ectasia after femtosecond laser-assisted smallincision lenticule extraction. J Cataract Refract Surg. 2015;41(4): 884-888.

11. Sachdev G, Sachdev MS, Sachdev R, Gupta H. Unilateral corneal ectasia following small-incision lenticule extraction. J Cataract Refract Surg. 2015;41(9):2014-2018.

12. Agca A, Ozgurhan EB, Demirok A, et al. Comparison of corneal hysteresis and corneal resistance factor after small incision lenticule extraction and femtosecond laser-assisted LASIK: a prospective fellow eye study. Cont Lens Anterior Eye. 2014;37(2):77-80.

Clinical Ophthalmology

\section{Publish your work in this journal}

Clinical Ophthalmology is an international, peer-reviewed journal covering all subspecialties within ophthalmology. Key topics include: Optometry; Visual science; Pharmacology and drug therapy in eye diseases; Basic Sciences; Primary and Secondary eye care; Patient Safety and Quality of Care Improvements. This journal is indexed on Submit your manuscript here: http://www.dovepress.com/clinical-ophthalmology-journal
13. Goldich Y, Barkana Y, Morad Y, Hartstein M, Avni I, Zadok D. Can we measure corneal biomechanical changes after collagen cross-linking in eyes with keratoconus? A pilot study. Cornea. 2009;28(5):498-502.

14. Al-Aqaba MA, Fares U, Suleman H, Lowe J, Dua HS. Architecture and distribution of human corneal nerves. Br J Ophthalmol. 2010;94(6): 784-789.

15. Ambrósio R Jr, Tervo T, Wilson SE. LASIK associated dry eye and neurotrophic epitheliopathy: pathophysiology and strategies for prevention and treatment. $J$ Refract Surg. 2008;24(4):396-407.

16. Demirok A, Ozgurhan EB, Agca A, et al. Corneal sensation after corneal refractive surgery with small incision lenticule extraction. Optom Vis Sci. 2013;90(10):1040-1047.

17. Asano-Kato N, Toda I, Hori-Komai Y, Takano Y, Tsubota K. Epithelial ingrowth after laser in situ keratomileusis: clinical features and possible mechanisms. Am J Ophthalmol. 2002;134(6):801-807.

18. Wang MY, Maloney RK. Epithelial ingrowth after laser in situ keratomileusis. Am J Ophthalmol. 2000;129(6):746-751.

19. Carr JD, Nardone R Jr, Sulting RD, Waring GO 3rd. Risk factors for epithelial ingrowth after LASIK. Invest Ophthalmol Vis Sci. 1997; 38(4):S232.

20. Caster AI, Friess DW, Schwendeman FJ. Incidence of epithelial ingrowth in primary and retreatment laser in situ keratomileusis. $J$ Cataract Refract Surg. 2010;36(1):97-101.

21. Gil-Cazorla R, Teus MA, de Benito-Llopis L, Fuentes I. Incidence of diffuse lamellar keratitis after laser in situ keratomileusis associated with the IntraLase $15 \mathrm{kHz}$ femtosecond laser and Moria M2 microkeratome. $J$ Cataract Refract Surg. 2008;34(1):28-31.

22. de Paula FH, Khairallah CG, Niziol LM, Musch DC, Shtein RM. Diffuse lamellar keratitis after laser in situ keratomileusis with femtosecond laser flap creation. J Cataract Refract Surg. 2012;38(6):1014-1019.

23. Chen S, Feng Y, Stojanovic A, Jankov MR 2nd, Wang Q. IntraLase femtosecond laser vs mechanical microkeratomes in LASIK for myopia: a systematic review and meta-analysis. J Refract Surg. 2012; 28(1):15-24.

24. Zhao J, He L, Yao P, et al. Diffuse lamellar keratitis after small incision lenticule extraction. J Refract Surg. 2015;41(2):400-407.

25. Demirok A, Agca A, Ozgurhan EB, et al. Femtosecond lenticule extraction for correction of myopia: a 6 month follow-up study. Clin Ophthalmol. 2013;7:1041-1047.

26. Shah R, Shah S, Sengupta S. Results of small incision lenticule extraction: all-in-one femtosecond laser refractive surgery. J Cataract Refract Surg. 2011;37(1):127-137.

27. Agca A, Ozgurhan EB, Yildirim Y, et al. Corneal backscatter analysis by in vivo confocal microscopy: fellow eye comparison of small incision lenticule extraction and femtosecond laser-assisted LASIK. J Ophthalmol. 2014;2014:265012.

28. Kamiya K, Shimizu K, Igarashi A, Kobashi H, Komatsu M. Comparison of visual acuity, higher-order aberrations and corneal asphericity after refractive lenticule extraction and wavefront-guided laser-assisted in situ keratomileusis for myopia. Br J Ophthalmol. 2013;97(8):968-975.

29. Vestergaard A, Ivarsen A, Asp S, Hjortdal JØ. Femtosecond (FS) laser vision correction procedure for moderate to high myopia: a prospective study of ReLEx ${ }^{\circledR}$ flex and comparison with a retrospective study of FS-laser in situ keratomileusis. Acta Ophthalmol. 2013;91(4):355-362.

\section{Dovepress}

PubMed Central and CAS, and is the official journal of The Society of Clinical Ophthalmology (SCO). The manuscript management system is completely online and includes a very quick and fair peer-review system, which is all easy to use. Visit http://www.dovepress.com/ testimonials.php to read real quotes from published authors. 